\title{
BMJ Open Effects of age and gender on the relationship between alcohol use disorder and somatic diseases: a national register study in Norway
}

\author{
Dawit Shawel Abebe (D , ,2 Lars Lien, ${ }^{1,3}$ Jørgen Gustav Bramness ${ }^{1,4,5}$
}

To cite: Abebe DS, Lien L, Bramness JG. Effects of age and gender on the relationship between alcohol use disorder and somatic diseases: a national register study in Norway. BMJ Open 2021;11:e050608. doi:10.1136/ bmjopen-2021-050608

- Prepublication history for this paper is available online. To view these files, please visit the journal online (http://dx.doi. org/10.1136/bmjopen-2021050608).

Received 24 February 2021 Accepted 26 October 2021

Check for updates

(c) Author(s) (or their employer(s)) 2021. Re-use permitted under CC BY-NC. No commercial re-use. See rights and permissions. Published by BMJ.

${ }^{1}$ Norwegian National Advisory Unit on Concurrent Substance Abuse and Mental Health Disorders, Innlandet Hospital Trust, Brumunddal, Norway

${ }^{2}$ Department of Nursing and Health Promotion, 0slo Metropolitan University, 0slo, Norway

${ }^{3}$ Faculty of Social and Health Sciences, Inland Norway University of Applied Sciences,

Elverum, Norway

${ }^{4}$ Department of Drug and Tobacco Research, Norwegian Institute of Public Health, Oslo, Norway

${ }^{5}$ Insitute of Clinical Medicine, UiT - The Arctic University of Norway, Troms $\emptyset$, Norway

Correspondence to

Professor Dawit Shawel Abebe; daab@oslomet.no

\section{ABSTRACT}

Objective This study aimed to examine how age and gender moderate the associations between alcohol use disorders (AUD) and several somatic diseases.

Design and setting We performed a retrospective, register-based cohort study with 6-year follow-up of patients with AUD and the general population. Data were acquired from the Norwegian Patient Registry. Cox regressions were used to estimate HRs of somatic diseases.

Participants Patients with AUD (17 023; 0.4\%) were compared with the population without AUD (4 271559 ; $99.6 \%$ ), with adults aged 18 years or older who were registered residents of Norway on 1 January 2008.

Main outcomes Dichotomous variables of 12 specific somatic diseases (cardiovascular diseases, endocrine, nutritional, and metabolic diseases, cancer, and infectious diseases) were assessed. Diagnoses were set in specialist healthcare services.

Results Patients with AUD, compared with a population without AUD, experienced a significantly greater burden of all studied somatic diseases. Middle-aged adults with AUD had increased risks $(p<0.05)$ for hypertension; ischaemic diseases; pulmonary diseases; cerebrovascular diseases; malnutrition; metabolic disorders; cancer; and influenza and pneumonia than younger and older adults with AUD. For most somatic diseases, we found no differences between younger versus older adults with AUD, and between females versus males with AUD ( $p>0.05)$. Males with AUD had significantly higher risks for pulmonary heart diseases $(\mathrm{HR}=3.9,95 \% \mathrm{Cl} 3.3$ to 4.6$)$ and metabolic disorders (HR 4.7, 95\% Cl 4.5 to 5.0), while females with AUD had a significantly higher risk for viral hepatitis ( $\mathrm{HR}=4.4,95 \% \mathrm{Cl} 3.8$ to 5.1 ).

Conclusions Age moderated the associations between AUD and most somatic diseases, with middle-aged adults with AUD having a greater increased risk of somatic diseases compared with younger and older adults with AUD. Gender only moderated associations between AUD and pulmonary heart diseases, metabolic disorders and viral hepatitis. This has implications for the prioritisation of somatic resources among patients with AUD.

\section{BACKGROUND}

Alcohol use disorder (AUD) is one of the leading risk factors for premature death and
Strengths and limitations of this study

- This study investigated how age and gender moderated the risks instigated by alcohol use disorders (AUDs) on somatic diseases, by addressing a comprehensive spectrum of somatic diseases with appropriate measurements and statistical methods.

- The use of national registries provided a large study population that gave adequate statistical power to detect differences across age groups and gender.

- We prospectively compared risks of different types of somatic diseases between patients with AUD compared with a population without AUD.

- Due to limited statistical power of analyse, our study could not differentiate the risks of somatic diseases related to age trends across gender.

The registries do not have information about severity of AUD or lifestyle factors.

disability globally, ${ }^{1}$ involving several somatic diseases. ${ }^{12}$ Literature suggests that this burden varies by age and gender, with some studies reporting alcohol use is associated with more health loss among adolescents and younger or middle-aged adults (15-49 years) than older, and in males more than in females. ${ }^{1-3}$ In contrast, review studies have reported that females with AUD alcohol have higher risks of developing certain somatic comorbidities (eg, cardiovascular diseases (CVDs), diabetes, alcoholic liver problems and breast cancer) compared with their male counterparts. ${ }^{4}$

Only a few epidemiological studies have investigated how age and gender moderate the risks instigated by alcohol on somatic diseases, particularly for CVDs like hypertension and ischaemic heart diseases. ${ }^{56}$ For instance, a large health examination survey conducted among men and women (20-69years old) in Japan found that the elevating effect of alcohol consumption on blood pressure is more prominent in the older population than in the young, while the elevating effect of alcohol drinking on serum high-density 
lipoprotein (HDL) cholesterol is not influenced by age. ${ }^{6}$ A similar recent study in South Korea revealed less significant associations of drinking levels with cardiovascular risk factors in women than in men. ${ }^{7}$ In contrast, a registerbased cohort study in Denmark reported comparable higher risks of a wide range of somatic diseases in those with alcohol-dependency in both genders. ${ }^{2}$

A moderating effect of age and gender on the relationship between alcohol use and somatic diseases is not consistent across studies. ${ }^{2}{ }^{5-7}$ This could be due to differences in the definition of alcohol use (eg, light and moderate alcohol intake vs heavy drinkers); differences in confounding factors; characteristics of study populations, study designs and statistical methods. Further, the underlying mechanisms explaining the above-stated agespecific and gender-specific findings are currently poorly understood. Alcohol may have graver health effects in the elderly due to changes in metabolism and distribution. ${ }^{8}$ There are also biological differences between genders; women absorb and metabolise alcohol differently than men. ${ }^{9}$ Women are often physically smaller than men and have a smaller fraction of body water and, therefore, achieve higher concentration of alcohol faster than men. This may also be related to gender differences in liver weight in relation to lean body mass. ${ }^{10}$ The genderspecific findings could also stem from psychosociocultural factors (eg, perceived differences in traditional gender roles) ${ }^{4}$ or differences in access to healthcare. ${ }^{11}$ Although women tend to seek treatment from mental health and primary care more readily than men, they are more likely to face barriers to treatment of addiction. ${ }^{11}$ However, recent findings indicate that such gender differences in AUD and alcohol-attributable somatic diseases are converging in many countries, especially in young cohorts. ${ }^{34}$

In general, the moderating effects of age and gender on alcohol-related somatic diseases remain underresearched, both in terms of a comprehensive spectrum of somatic diseases, and in terms of appropriate methods of measurement. Epidemiological studies are therefore needed to assess the varying relationship between alcohol and somatic diseases across age groups and gender. Such assessment of moderating effects of age and gender provides crucial input for healthcare professionals in determining and allocating resources as well as identifying specific risk factors that may be targeted in preventive interventions. It can also further help treatment programmes to offer age-specific and gender-specific services. The present study thus aims to examine the moderating effects of age and gender on the relation between AUD and development of a wide range of specific somatic diseases (ie, four CVDs; four endocrine, nutritional and metabolic diseases; cancer; and three infectious diseases) across the life coursefrom young adults to later life-compared with a nonAUD population.

\section{METHODS}

\section{Study design}

The study is a retrospective, register-based cohort study (2008-2016) combining sociodemographic information from Statistics Norway and information on somatic diseases and mental disorders obtained from the Norwegian Patient Registry (NPR).

\section{Setting, participants}

The sampling framework consisted of all individuals aged 18 years or older who were legal residents in Norway on 1 January $2008(\mathrm{~N}=4652$ 365). The $(\mathrm{N}=22512)$ patients with AUD were identified during the preceding 2 years (2008-2009) and were then followed until the registration of somatic diseases from 1 January 2010, through 31 December 2016. Patients who were registered as deceased ( $\mathrm{N}=363783)$ during the study period (2008-2016) were excluded from analysis. The final sample included for analysis consisted of $17023(0.4 \%)$ patients with AUD, and $4271559(99.6 \%)$ persons without AUD as a comparison (control) group.

\section{Outcomes and explanatory variables}

NPR holds data on all registered diagnoses obtained during contacts with specialist healthcare services. All mental and somatic diagnoses were received during outpatient and inpatient contacts with specialist healthcare according to the International Classification of Diseases (ICD), 10th Revision between 1 January 2008 and 31 December 2016. AUD are diagnosed based on ICD-10, chapter V on mental and behavioural disorders. Specifically, it includes all alcohol disorders in the F10 block. AUD diagnoses were provided by psychologists or psychiatrists during outpatient and inpatient contacts with the specialist mental healthcare service between 2008 and 2016. The number of participants visits (registered with AUD) in 2008 was $8832(0.2 \%) ; 11929(0.3 \%)$ in $2009 ; 13144(0.3 \%)$ in $2010 ; 14006(0.3 \%)$ in 2011 ; $14708(0.3 \%)$ in $2012 ; 14944(0.4 \%)$ in $2013 ; 15315$ in $2014(0.4 \%) ; 15903(0.4 \%)$ in 2015 , and $16609(0.4 \%)$ in 2016. Table 1 presents the dichotomous variables representing AUD as an explanatory variable, and somatic diseases as event outcome variables, including the year of diagnosis.

\section{Covariates}

Age, gender, mental disorders and level of education were used as covariate variables. The age variable (per 1 January 2008) was first used as a continuous variable, and then categorised into three strata: younger adult (18-35 years), middle-aged adult (26-65 years) and older adult (66 and above years). Gender was coded 0 for males and 1 for females. Mental disorders were diagnosed based on ICD-10, chapter V on mental and behavioural disorders, excluding those with AUD. The participants' highest level of education was coded as $0=$ primary, $1=$ secondary, and $2=$ college and university, and regards an index for the socioeconomic status. 


\begin{tabular}{|c|c|c|}
\hline & $\begin{array}{l}\text { ICD-10 } \\
\text { codes }\end{array}$ & $\begin{array}{l}\text { Year of } \\
\text { diagnosis }\end{array}$ \\
\hline \multicolumn{3}{|c|}{ Explanatory (independent) variables } \\
\hline AUD & F10 & 2008-2009 \\
\hline \multicolumn{3}{|l|}{ Event outcome variables } \\
\hline \multicolumn{3}{|l|}{ Cardiovascular diseases } \\
\hline Hypertensive diseases & $|10-| 19$ & 2010-2016 \\
\hline Ischaemic diseases & $120-\mid 29$ & 2010-2016 \\
\hline Pulmonary diseases & $\mathrm{I} 26-\mathrm{I} 28$ & 2010-2016 \\
\hline Cerebrovascular diseases & $160-199$ & 2010-2016 \\
\hline \multicolumn{3}{|c|}{ Endocrine, nutritional and metabolic diseases } \\
\hline Diabetes mellitus & E10-E14 & 2010-2016 \\
\hline Malnutrition & E40-E46 & 2010-2016 \\
\hline Obesity & E66 & 2010-2016 \\
\hline Metabolic disorders & E70-E90 & 2010-2016 \\
\hline Cancer & $\mathrm{C} 00-\mathrm{C} 97$ & 2010-2016 \\
\hline \multicolumn{3}{|l|}{ Infectious diseases } \\
\hline Viral hepatitis & B15-B19 & 2010-2016 \\
\hline Influenza and pneumonia & J09-J18 & 2010-2016 \\
\hline $\begin{array}{l}\text { Chronic lower respiratory } \\
\text { diseases }\end{array}$ & J40-J47 & 2010-2016 \\
\hline
\end{tabular}

AUD, alcohol use disorders; ICD, The International Classification of Diseases, 10th Revision

\section{Statistical analysis}

$\chi^{2}$ tests were applied to compare differences in the proportions of somatic diseases between patients with AUD and the general population (see table 2). The Cox proportional regression models were applied to estimate the risks of somatic diseases (event outcomes) among patients with AUD (an independent risk factor). HRs with $95 \%$ CIs were reported, with calendar time as the underlying time axis. A stepwise regression was applied: model 0 present unadjusted HR estimates; HR estimates in model 1 were adjusted for age, gender, mental disorders and level of education, and HR estimates in models 2 and 3 present the interaction effects of AUD with age and gender, respectively (include both main effects and interaction terms; see table 3). Further, stratified Cox models were fitted for each group and gender (see table 4). Estimates were judged as statistically significant when $p$ values $\leq 0.05$. Moreover, to determine whether the HRs estimates in the stratified Cox models across age groups or between males and females were statistically significant, the $95 \%$ CIs of HRs were compared. If the CIs overlapped, the differences between age groups or gender would not be statistically significant. If there was no overlap, the difference would be significant. The analyses were performed using Stata SE/16.

\section{Patient and public involvement}

This was a retrospective registry study; neither the patients nor the members of public were not involved in the design, data collection, analysis or reporting of our findings. The study was conducted with the benefit of the patients in mind.

\section{RESULTS}

\section{Participant characteristics}

The descriptive summary of study population is presented in table 2. The proportions of most somatic diseases are at least twice as high in patients with AUD compared with individuals without AUD, except for cancer (ie, 5.8\% among those without AUD vs $6.9 \%$ among patients with AUD). Patients with AUD experienced a higher burden of metabolic disorders (16.5\%), hypertension (13.6\%) and chronic lower respiratory diseases $(12.8 \%)$. The mean age at which a first diagnosis of somatic diseases occurs shows that patients with AUD were diagnosed at much younger age (about 5-15 years earlier) than those without AUD, while such age differences were smaller for obesity, viral hepatitis and chronic lower respiratory diseases. The gender proportions of somatic diseases are also more skewed in patients with AUD, with fewer females with AUD diagnosed with somatic diseases compared with females in the population without AUD.

Moreover, 53\% ( $\mathrm{N}=8998)$ patients with AUD had comorbid mental disorders while only $4 \%(161,064)$ of those without AUD had mental disorders. The proportion of patients with AUD with primary and higher education were $42 \%$ (7061) and 17\% (2798), respectively, whereas these proportions were 22\% (703 467) and 35\% (1 140 724) among those without AUD.

\section{Moderating effects of age and gender}

Table 3 presents results (HR with 95\% CI) from the Cox regression models, where somatic diseases added as an event outcome and AUD was added as an explanatory independent variable. A stepwise regression model was applied: HR estimates in model 0 were unadjusted estimates; model 1 presents estimates that were adjusted to age, gender, level of education and mental disorders, and models 2 and 3 present adjusted estimates with the interaction effects of AUD with age and gender, respectively. The adjusted HR estimates in model 1 illustrate that the HRs of all somatic diseases were significantly higher among patients with AUD, ranging from 1.4-fold for obesity (95\% CI 1.2 to 1.6 ) to 6.4-fold for viral hepatitis (95\% CI 5.8 to 7.1). In model 2, the age and AUD interaction terms indicate that the risk of developing all somatic diseases was statistically significantly moderated by age. In model 3, the gender and AUD interaction terms show that the risk of developing hypertension; pulmonary heart diseases; cerebrovascular diseases; metabolic disorders; viral hepatitis, and influenza and pneumonia statistically significantly moderated by gender. Gender effects for ischaemic heart diseases, diabetes mellitus, malnutrition, 


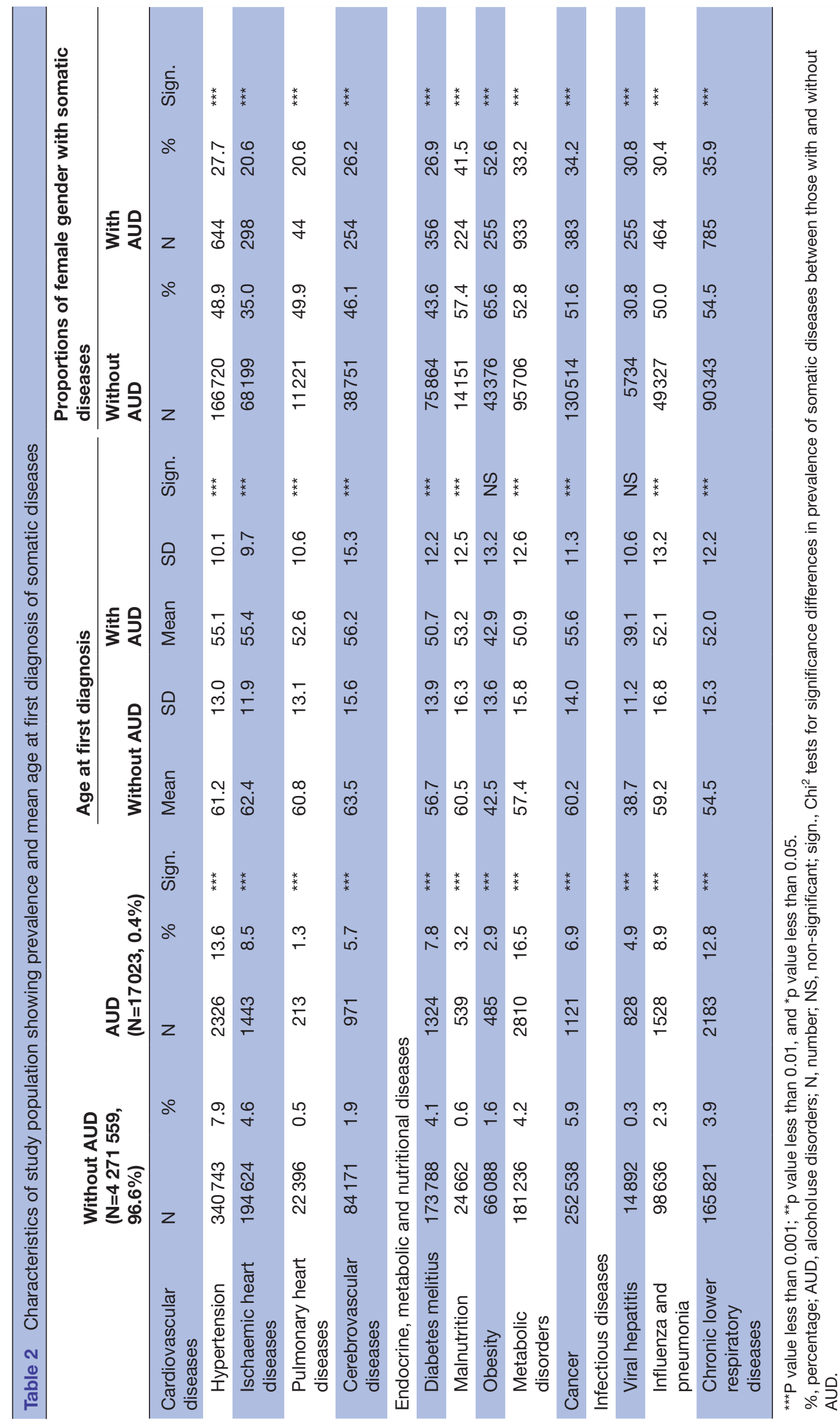


Table 3 Stepwise Cox regression models showing HRs of somatic diseases and interaction effects of age and gender among persons with alcohol use disorder (AUD) compared with those without AUD

\begin{tabular}{|c|c|c|c|c|}
\hline & $\begin{array}{l}\text { Model } 0 \\
\text { (unadjusted) }\end{array}$ & $\begin{array}{l}\text { Model } 1 \\
\text { (adjusted) }\end{array}$ & $\begin{array}{l}\text { Model } 2 \text { (the interaction } \\
\text { term between age and } \\
\text { AUD) }\end{array}$ & $\begin{array}{l}\text { Model } 3 \text { (the interaction } \\
\text { term between gender } \\
\text { and AUD) }\end{array}$ \\
\hline & HR $(95 \% \mathrm{Cl})$ & HR $(95 \% \mathrm{Cl})$ & $P$ value & $P$ value \\
\hline \multicolumn{5}{|l|}{ Cardiovascular diseases } \\
\hline Hypertension & 4.6 (4.4 to 4.8$)$ & 2.6 (2.5 to 2.7$)$ & $<0.001$ & $<0.001$ \\
\hline Ischaemic heart diseases & 5.5 (5.2 to 5.8$)$ & 2.5 (2.4 to 2.6$)$ & $<0.001$ & NS \\
\hline Pulmonary heart diseases & 6.8 (5.9 to 7.8$)$ & 3.1 (2.7 to 3.6$)$ & $<0.001$ & $<0.001$ \\
\hline Cerebrovascular diseases & 8.0 (7.5 to 8.5$)$ & 3.8 (3.6 to 4.1$)$ & $<0.001$ & $<0.001$ \\
\hline \multicolumn{5}{|l|}{$\begin{array}{l}\text { Endocrine, metabolic and } \\
\text { nutritional diseases }\end{array}$} \\
\hline Diabetes melitius & 4.9 (4.6 to 5.2$)$ & 1.9 (1.8 to 2.1$)$ & $<0.001$ & NS \\
\hline Malnutrition & 18.3 (16.8 to 20.0$)$ & 6.4 (5.8 to 7.1$)$ & $<0.001$ & NS \\
\hline Obesity & 4.8 (4.4 to 5.3$)$ & $1.4(1.2$ to 1.6$)$ & $<0.001$ & NS \\
\hline Metabolic disorders & $11.1(10.6$ to 11.5$)$ & 4.5 (4.3 to 4.6$)$ & $<0.001$ & $<0.01$ \\
\hline Cancer & 2.9 (2.8 to 3.2 ) & 1.9 (1.8 to 2.1$)$ & $<0.05$ & NS \\
\hline \multicolumn{5}{|l|}{ Infectious diseases } \\
\hline Viral hepatitis & 35.5 (33.9 to 38.2) & 3.3 (3.1 to 3.6 ) & $<0.001$ & $<0.05$ \\
\hline Influenza and pneumonia & $11.3(10.7$ to 11.9$)$ & 4.1 (3.9 to 4.3 ) & $<0.001$ & $<0.05$ \\
\hline $\begin{array}{l}\text { Chronic lower respiratory } \\
\text { diseases }\end{array}$ & 9.5 (9.1 to 10.1$)$ & 3.5 (3.3 to 3.6 ) & $<0.001$ & NS \\
\hline
\end{tabular}

Estimates in models 1-3 are adjusted to age, gender, level of education and comorbid mental disorders.

AUD, alcohol use disorders; NS, statistically non-significant at $p$-values less than 0 .

obesity and chronic lower respiratory diseases were nonstatistically significant.

In table 4, we further conducted stratified analyses for the statistically significant interaction terms: fitting a model for each age group (ie, younger adult (18-35 years), middle-aged adult (36-65) and older adult (66 and above years)) and gender, separately. Such stratified analyses simplify the interpretations of interaction estimates in table 3 (models 2 and 3). The HR estimates further showed statistically significant variations of such risks among patients with AUD depending on age and gender, except for obesity and viral hepatitis which presented statistically non-significant age and gender effects.

In all types of CVDs, malnutrition, metabolic disorders, cancer, and influenza and pneumonia, and chronic lower respiratory diseases, middle-aged adults with AUD had significantly higher HRs than older adults with AUD. middle-aged adults with AUD had also significantly higher HRs for hypertension, cerebrovascular diseases, malnutrition, metabolic disorders, influenza and pneumonia, and chronic lower respiratory diseases compared with younger adults with AUD, whereas the HRs for ischaemic and pulmonary heart diseases, obesity, cancer and viral hepatitis were not statically significant between younger and middle-aged adults with AUD. The differences in HRs of most somatic diseases between younger and older adults with AUD were not statically significant, except for malnutrition and chronic lower respiratory diseases. Older adults with AUD had significantly higher HRs for malnutrition (4.6, 95\% CI 3.9 to 5.5) and chronic lower respiratory diseases $(3.4,95 \%$ CI 3.1 to 3.8$)$ compared with younger adults with AUD. Non-significant age differences among patients with AUD were documented for diabetes and viral hepatitis.

The gender effects showed that males with AUD had significantly higher HRs for pulmonary heart diseases (3.9, 95\% CI 3.3 to 4.6$)$ and metabolic disorders (4.7, 95\% CI 4.5 to 5.0) compared with females with AUD. Females with AUD had significantly higher HRs for viral hepatitis $(4.4,95 \%$ CI 3.8 to 5.1) compared with males with AUD. Although we found significant interactions terms of gender for hypertension, cerebrovascular diseases and influenza and pneumonia, the stratified HRs did not show statistical significance. Moreover, nonsignificant differences in HRs were found for ischaemic diseases, malnutrition, obesity and viral hepatitis between males and females with AUD.

\section{DISCUSSION}

In this large retrospective, register-based national cohort study, patients with AUD demonstrated an excessive risk for all studied somatic diseases (ie, CVDs, endocrine, nutritional, and metabolic diseases, cancer, and infectious 
Table 4 Age-based and gender-based stratified Cox regression models showing adjusted HRs of somatic diseases among persons with alcohol use disorder (AUD)

\begin{tabular}{|c|c|c|c|c|c|}
\hline & $\begin{array}{l}18-35 \text { years } \\
\text { HR }(95 \% \mathrm{Cl})\end{array}$ & $\begin{array}{l}36-65 \text { years } \\
\text { HR }(95 \% \mathrm{Cl})\end{array}$ & $\begin{array}{l}\text { 66+years } \\
\text { HR }(95 \% \mathrm{CI})\end{array}$ & $\begin{array}{l}\text { Males } \\
\text { HR }(95 \% \mathrm{Cl})\end{array}$ & $\begin{array}{l}\text { Females } \\
\text { HR }(95 \% \mathrm{Cl})\end{array}$ \\
\hline \multicolumn{6}{|l|}{$\begin{array}{l}\text { Cardiovascular } \\
\text { diseases }\end{array}$} \\
\hline Hypertension & 2.3 (1.8 to 2.8$)$ & 2.6 (2.4 to 2.7$)$ & 2.0 (1.8 to 2.2$)$ & 2.7 (2.6 to 2.8$)$ & 2.4 (2.2 to 2.6 \\
\hline $\begin{array}{l}\text { Ischaemic heart } \\
\text { diseases }\end{array}$ & 2.5 (1.8 to 3.5$)$ & 2.5 (2.3 to 2.7 ) & 1.7 (1.5 to 1.9$)$ & - & - \\
\hline $\begin{array}{l}\text { Pulmonary heart } \\
\text { diseases }\end{array}$ & $2.2(1.4$ to 3.5$)$ & 3.6 (3.1 to 4.4$)$ & 2.1 (1.6 to 2.7$)$ & 3.9 (3.3 to 4.6$)$ & 1.8 (1.3 to 2.4 \\
\hline $\begin{array}{l}\text { Cerebrovascular } \\
\text { diseases }\end{array}$ & 2.8 (2.0 to 3.9$)$ & 4.4 (4.0 to 4.8$)$ & 2.5 (2.2 to 2.8$)$ & 4.0 (3.7 to 4.3$)$ & 3.5 (3.1 to 4.0 \\
\hline \multicolumn{6}{|c|}{ Endocrine, metabolic and nutritional diseases } \\
\hline Diabetes melitius & 2.2 (1.8 to 2.6$)$ & 1.9 (1.8 to 2.0$)$ & $1.6(1.4$ to 1.8$)$ & - & - \\
\hline Malnutrition & $2.6(1.9$ to 3.5$)$ & 8.4 (7.5 to 9.5$)$ & 4.6 (3.9 to 5.5$)$ & - & - \\
\hline Obesity & $1.4(1.2$ to 1.6$)$ & $1.2(1.1$ to 1.4$)$ & 2.1 (1.6 to 2.9$)$ & - & - \\
\hline Metabolic disorders & 3.4 (3.0 to 3.8$)$ & $4.8(4.6$ to 5.1$)$ & 3.5 (3.2 to 3.8$)$ & 4.7 (4.5 to 5.0$)$ & 4.1 (3.8 to 4.3 \\
\hline Cancer & 1.7 (1.4 to 2.2$)$ & 2.1 (1.9 to 2.2$)$ & 1.5 (1.3 to 1.6$)$ & - & - \\
\hline \multicolumn{6}{|l|}{ Infectious diseases } \\
\hline Viral hepatitis & 2.9 (2.6 to 3.3$)$ & 3.2 (2.8 to 3.5$)$ & 3.2 (2.9 to 3.6$)$ & 2.7 (2.5 to 3.0 ) & 4.4 (3.8 to 5.1 \\
\hline $\begin{array}{l}\text { Influenza and } \\
\text { pneumonia }\end{array}$ & 3.1 (2.7 to 3.7 ) & 4.6 (4.3 to 4.9$)$ & 3.2 (2.9 to 3.6 ) & 4.3 (4.0 to 4.6$)$ & 3.7 (3.4 to 4.1 \\
\hline $\begin{array}{l}\text { Chronic lower } \\
\text { respiratory diseases }\end{array}$ & 2.4 (2.1 to 2.7 ) & 3.6 (3.4 to 3.8 ) & 3.4 (3.1 to 3.8 ) & - & - \\
\hline
\end{tabular}

Age-specific HR estimates are adjusted to gender, level of education and comorbid mental disorders. Gender-specific HR estimates are adjusted to age, level of education and comorbid mental disorders. AUD, alcohol use disorders.

diseases) compared with the population without AUD across all age groups and genders. We found that the increased risks of somatic diseases among patients with AUD differed depending on age groups, gender and types of somatic diseases. For instance, middle-aged adult patients with AUD (36-65 years) had increased risks of hypertension, cerebrovascular diseases, malnutrition, metabolic disorders, influenza and pneumonia, and chronic lower respiratory compared with younger and older adults with AUD. However, we did not document a moderating effect of age for diabetes or viral hepatitis.

In the present study, the adjusted HRs of all somatic diseases were higher in patients with AUD than in the population without AUD, ranging from 1.4-fold risk for cancer to 6.4-fold risk for viral hepatitis. Such excessive risks of somatic diseases are also found in prior studies. ${ }^{2}{ }^{12}$ Although some studies reported mixed findings whether alcohol dependency increased the risk of some somatic diseases (eg, diabetes, and coronary heart related diseases), ${ }^{2}{ }^{12}$ we consistently identified patients with AUD with elevated risks for all somatic diseases investigated in the present study. The elevated risks of somatic diseases among patients with AUD is commonly related to psychiatric comorbidity (ie, major depression, bipolar and PTSD), ${ }^{13} 14$ poor socioeconomic status and lifestyle factors (eg, physical inactivity, poor dietary habits and smoking), ${ }^{15-17}$ or consequences of alcohol's adverse effects on the immune system. ${ }^{18}$ High levels of disparity in accessing and using healthcare services ${ }^{19-21}$ and side effects of psychotropic medications might also play a pivotal role. ${ }^{13}$ For instance, the treatment gap for AUD is larger than for any other mental disorder, with less than $10 \%$ treated in Europe or the USA. ${ }^{22}$ Even simple screening measures for obesity and blood pressure are very low among substance use disorder patients. ${ }^{15324}$

The overall increased risks of the majority somatic diseases in patients with AUD aged 36-65 years could be due to more psychiatric comorbidities compared with the general population, and relatively higher utilisation of healthcare services compared with older adult patients with AUD. ${ }^{25}$ However, underdiagnoses or under treatment of $\mathrm{AUD}^{26}$ and a higher mortality rate in the older age group may contribute to underestimations of risks of somatic diseases. ${ }^{27}$ It could also relate to age differences in the frequency and quantity of alcohol drinking, where both the frequency of heavy episodic drinking and the quantities reported to be drunk decrease by age. ${ }^{28}$

Furthermore, we found that most somatic diseases do not significantly vary between females and males with AUD, except for pulmonary heart diseases, metabolic 
disorders and viral hepatitis. As stated in the Introduction section, our finding reflects the convergence in alcohol consumption and alcohol-related problems between females and males. ${ }^{34}$ Prior studies documented divergent findings reporting either a higher risk among males with AUD or no gender differences in somatic symptoms and diseases $^{425}$ or alcohol-dependent women reported more somatic diseases, for example, liver disease ${ }^{9}$ and CVDs (eg, cardiomyopathy and myopathy). ${ }^{29}$ These gender differences may be attributable to differential biological mechanisms, ${ }^{9}$ and a lower utilisation of addiction treatment. ${ }^{1130}$ On the other hand, the elevated risks of somatic diseases among males with AUD may relate to differences in drinking patterns, where men have higher drinking levels, earlier onset of problematic alcohol consumption and longer duration of problematic consumption than women. ${ }^{25}$ Moreover, it could stem from gender differences in types of beverages, where men frequently drink beer and spirits in a larger quantity, while women prefer wine. $^{28}$

This study brings several methodological advantages in the use of NPR. First, the coverage of healthcare services and the quality of health records in Norway is considered to be high, which facilitates representativeness and reduces selection bias. ${ }^{32}$ There are, however, also limitations to this approach. As stated above, AUD is hugely under treated in specialist healthcare ${ }^{26}$ and somatic disorders are undertreated among those with alcohol and substance abuse, ${ }^{33}$ the first possibly leading to an overestimation of the effect, and the latter an underestimation. Second, our research is based on clinically set diagnosis from specialist care, which may or may not be reliable. It is, however, unlikely that there is systematic difference between the AUD and non-AUD groups, thus making the relative estimates valid. Third, a larger study population brings adequate statistical power to detect differences across age groups and gender. Finally, we prospectively compared risks of different types of somatic diseases between patients with AUD compared with the population without AUD, as well as applying appropriate statistical methods to examine moderating effects of age and gender. The main limitation of this study is that, in order to ensure the statistical power of analysis, we could not differentiate the risks of somatic diseases related to age trends across gender, and among specific types of cancer. Furthermore, the registries do not have information about severity of AUD (eg, volume and frequency of consumption); onset and duration of problematic alcohol consumption; and estimates were not adequately adjusted to potential confounders, that is, lifestyle factors.

\section{Implications}

Our findings suggest that the elevated risk of somatic diseases reveals that screening for medical problems should be more routinely incorporated into addiction treatments at primary and secondary healthcare settings. This may help to identify somatic problems earlier and reduce the development of more severe forms of somatic diseases, while simultaneously reducing detrimental effects of alcohol consumption on underlying conditions. In particular, our finding imply that preventive and treatment programmes should pay greater attention to middle-aged adults with AUD.

Contributors DSA: analysed and interpreted data; drafted and revised the manuscript; approved the final manuscript. LL and JGB contributed substantially to the study concept and design; interpreting the results; and drafting and critically revised the manuscript.DSA is responsible for the overall content as the guarantor.

Funding The research was funded from the Southern and Eastern Norway Regional Health Authority through the research project awarded to Professor Abebe 'Patterns and courses of somatic illness and the utilisation of health services among patients with substance use disorders and/or mental disorders in Norway' (project number 150901).

Disclaimer The funder had no role in study design, data collection, data analysis, data interpretation, or writing of the report.

Competing interests None declared.

Patient and public involvement Patients and/or the public were not involved in the design, or conduct, or reporting, or dissemination plans of this research.

Patient consent for publication Not applicable.

Ethics approval All study procedures were approved by the Norwegian Regional Committee for Medical and Health Research Ethics (ref: 17/26919-5).

Provenance and peer review Not commissioned; externally peer reviewed.

Data availability statement Data are available upon reasonable request. The data file was constructed from administrative registers managed by Statistics Norway, Norwegian Patient Register, and Norwegian Directorate of Health. The register data can be made available for research projects approved by the Norwegian Regional Committee for Medical and Health Research Ethics and Norwegian Data Protection Authority.

Open access This is an open access article distributed in accordance with the Creative Commons Attribution Non Commercial (CC BY-NC 4.0) license, which permits others to distribute, remix, adapt, build upon this work non-commercially, and license their derivative works on different terms, provided the original work is properly cited, appropriate credit is given, any changes made indicated, and the use is non-commercial. See: http://creativecommons.org/licenses/by-nc/4.0/.

ORCID iD

Dawit Shawel Abebe http://orcid.org/0000-0002-5184-0478

\section{REFERENCES}

1 Griswold MG, Fullman N, Hawley C, et al. Alcohol use and burden for 195 countries and territories, 1990-2016: a systematic analysis for the global burden of disease study 2016. The Lancet 2018;392:1015-35.

2 Holst C, Tolstrup JS, Sørensen HJ, et al. Alcohol dependence and risk of somatic diseases and mortality: a cohort study in 19002 men and women attending alcohol treatment. Addiction 2017;112:1358-66.

3 WHO. Global status report on alcohol and health 2018. Geneva: WHO, 2018.

4 Erol A, Karpyak VM. Sex and gender-related differences in alcohol use and its consequences: contemporary knowledge and future research considerations. Drug Alcohol Depend 2015;156:1-13.

5 Shield KD, Parry C, Rehm J. Chronic diseases and conditions related to alcohol use. Alcohol research: current reviews 2014;35:155.

6 Wakabayashi I, Araki Y. Influences of gender and age on relationships between alcohol drinking and atherosclerotic risk factors. Alcohol Clin Exp Res 2010;34(Suppl 1):S54-60.

7 Lee K. Sex-Specific associations of Risk-Based alcohol drinking level with cardiovascular risk factors and the 10-year cardiovascular disease risk scores. Alcohol Clin Exp Res 2018;42:1503-10.

8 Meier P, Seitz HK. Age, alcohol metabolism and liver disease. Curr Opin Clin Nutr Metab Care 2008;11:21-6.

9 Frezza M, di Padova C, Pozzato G, et al. High blood alcohol levels in women. The role of decreased gastric alcohol dehydrogenase activity and first-pass metabolism. N Engl J Med 1990;322:95-9. 
10 Jones AW. Evidence-based survey of the elimination rates of ethanol from blood with applications in forensic casework. Forensic Sci Int 2010;200:1-20.

11 Green CA. Gender and use of substance abuse treatment services. Alcohol Res Health 2006;29:55.

12 Schoepf D, Heun R. Alcohol dependence and physical comorbidity: increased prevalence but reduced relevance of individual comorbidities for hospital-based mortality during a 12.5-year observation period in general Hospital admissions in urban northwest England. Eur Psychiatry 2015;30:459-68.

13 Vancampfort D, Hallgren M, Mugisha J, et al. The prevalence of metabolic syndrome in alcohol use disorders: a systematic review and meta-analysis. Alcohol Alcohol 2016;51:515-21.

14 Nesvåg R, Knudsen GP, Bakken IJ, et al. Substance use disorders in schizophrenia, bipolar disorder, and depressive illness: a registrybased study. Soc Psychiatry Psychiatr Epidemiol 2015;50:1267-76.

15 Hert M, Vancamport D, Detraux J. Somatic Problems and Dual Disorder Patients. In: Greet D, Moggi F, eds. Co-Occurring Addictiv and psychiatric disorders: a practice-based Handbook from a European perspective. London: Springer, 2015: 349-61.

16 Kelly PJ, Baker AL, Deane FP, et al. Prevalence of smoking and other health risk factors in people attending residential substance abuse treatment. Drug Alcohol Rev 2012;31:638-44.

17 Mendelsohn CP, Wodak Am A. Smoking cessation in people with alcohol and other drug problems. Aust Fam Physician 2016;45:569

18 Szabo G, Saha B. Alcohol's effect on host defense. Alcohol Res 2015;37:159.

19 Harris KM, Edlund MJ. Use of mental health care and substance abuse treatment among adults with co-occurring disorders. Psychiatr Serv 2005;56:954-9.

20 Ziedonis DM, Smelson D, Rosenthal RN, et al. Improving the care of individuals with schizophrenia and substance use disorders: consensus recommendations. J Psychiatr Pract 2005;11:315-39.

21 Toender A, Munk-Olsen T, Vestergaard M, et al. Impact of severe mental illness on cancer stage at diagnosis and subsequent mortality: a population-based register study. Schizophr Res 2018;201:62-9.
22 Roerecke M, Rehm J. Cause-specific mortality risk in alcohol use disorder treatment patients: a systematic review and meta-analysis. Int J Epidemiol 2014;43:906-19.

23 DE Hert M, Correll CU, Bobes J, et al. Physical illness in patients with severe mental disorders. I. Prevalence, impact of medications and disparities in health care. World Psychiatry 2011;10:52-77.

24 Stephens KA, West II, Hallgren KA, et al. Service utilization and chronic condition outcomes among primary care patients with substance use disorders and co-occurring chronic conditions. $J$ Subst Abuse Treat 2020;112:49-55.

25 Berglund K, Berggren U, Fahlke C, et al. Self-reported health functioning in Swedish alcohol-dependent individuals: age and gender perspectives. Nord J Psychiatry 2008;62:405-12.

26 Torvik FA, Ystrom E, Gustavson K, et al. Diagnostic and genetic overlap of three common mental disorders in structured interviews and health registries. Acta Psychiatr Scand 2018;137:54-64.

27 Han B, Gfroerer JC, Colliver JD, et al. Substance use disorder among older adults in the United States in 2020. Addiction 2009;104:88-96.

28 Mäkelä P, Gmel G, Grittner U, et al. Drinking patterns and their gender differences in Europe. Alcohol Alcohol Suppl 2006;41:i8-18.

29 Urbano-Márquez A, Estruch R, Fernández-Solá J, et al. The greater risk of alcoholic cardiomyopathy and myopathy in women compared with men. JAMA 1995;274:149-54

30 Vijayasiri G, Richman JA, Rospenda KM. The great recession, somatic symptomatology and alcohol use and abuse. Addict Behav 2012;37:1019-24.

31 Cho Y, Shin S-Y, Won S, et al. Alcohol intake and cardiovascular risk factors: a Mendelian randomisation study. Sci Rep 2015;5:18422

32 Thygesen LC, Ersbøll AK. When the entire population is the sample: strengths and limitations in register-based epidemiology. Eur $J$ Epidemiol 2014;29:551-8.

33 Heiberg $\mathrm{IH}$, Jacobsen BK, Nesvåg R, et al. Total and cause-specific standardized mortality ratios in patients with schizophrenia and/or substance use disorder. PLoS One 2018;13:e0202028. 